\title{
Computer Aided Design and Project Management
}

\section{Prof. Martin William Weiser, Eastern Washington University}

Martin Weiser is an Assistant Professor in the Engineering and Design Department at Eastern Washington University. He earned his BS in Ceramic Engineering from the Ohio State University and his MS and $\mathrm{PhD}$ in Materials Science and Mineral Engineering from the University of California at Berkeley. He then joined the Mechanical Engineering department at the University of New Mexico where he taught Materials Science, Thermodynamics, Manufacturing Engineering, and Technical Communication. Martin then joined Johnson Matthey Electronics/Honeywell Electronic Materials where he held positions in Technical Service, Product Management, Six Sigma, and Research \& Development. He is an inventor on a dozen patents and patent applications and has published over 30 papers and book chapters on topics including ceramic processing, $\mathrm{Pb}$-free solder development, experimental design, and biomechanics. His current research focuses on rocket propellant characterization, fin flutter, and heat transfer.

\section{Dr. Hani Serhal Saad, Eastern Washington University \\ Dr. Kyle Frederick Larsen P.E., Eastern Washington University}

Dr. Kyle Frederick Larsen Currently teaching Mechanical Engineering at Eastern Washington University Ph.D. Mechanical Engineering Brigham Young University M.S. Mechanical Engineering California State University Sacramento B.S. Mechanical Engineering California State University Sacramento 


\title{
Computer Aided Design and Project Management
}

\begin{abstract}
At Eastern Washington University (EWU), we teach a class titled Computer-Aided Design and Project Management to a combination of Mechanical Engineering Technology (MET) and other Technology students. This course is not what is usually associated with the term CAD, but rather an introduction to project management and spreadsheets as an Engineering design tool. The class has a very strong hands-on component using Microsoft Excel and MS Project. The students are then required to use both tools in their later courses, particularly in their laboratory courses and planning/tracking of the Capstone Design course. These students also take a Technical Writing course from the English Department to prepare them for report writing.
\end{abstract}

We use several assignments of increasing difficulty to expose the students to Excel as a design tool and Project to organize and track a project. The quarter culminates with small teams of students using both tools to design, plan, and track a virtual project of their choice such as starting a small company, building a structure, or installing equipment in a plant. The teams must submit a report and make a semi-formal presentation to the class and instructor.

As part of our continuous improvement effort, we assess nine course objectives. We will present a statistical analysis of how well both the students and instructor believe the objectives were met. The analysis includes for several instructors, several years, and both MET students who must take two quarters of calculus and Technology students who take pre-calculus. We also teach an accelerated version of the course titled "laboratory analysis and reports" that also incorporates a large technical writing component to our ME students and we will include anecdotal data from that course.

\section{Background}

The need for the class is to ensure that the students enrolled in the MET or Construction Management programs at Eastern Washington University are exposed to project management (PM) and Microsoft Excel. The idea is to provide the students with enough material for them to be able to manage a project, analyze data and present the work in a coherent and professional way. Indeed, it is crucial for the student to be able to present their ideas and work to fellow engineers and non-engineers alike. One part of the course consisted of project management using Microsoft Project while the second dealt with Microsoft Excel. Teaching project management to engineering students can be challenging, just like any 'non engineering' or 'non mathematical' topic. The students tend to think of these skills as non-essential to their technical background, not realizing that part of their work will require proper communication and project management. Because of this an emphasis is placed on the necessity nowadays to have a complete and thorough management of projects as well as the oral presentation. In addition, to highlight the importance of such an approach, the students are required to use their knowledge of PM and Microsoft Project in their Capstone course. They are required to have their project laid out using Microsoft Project including all the necessary constraints, costs, schedule, etc. They are required to do so from the very start, and any subsequent changes must be documented as part of the work. This has the advantage of having the students apply their knowledge of the software to a 
well defined and relatively involved project. They are also required to present their work to the rest of the class, the faculty, and representatives from local industry. While PM in general and Microsoft Project in particular can be more involved than what is covered in the 4 contact hour course, the students should be able, to perform the tasks from the course objectives as listed in Table I which are listed in the order from the syllabus. The idea is to give them enough information and make them comfortable enough working with the software for them to be able to learn to use the more advanced features as needed.

Table I Course Objectives related to Project Management

3. Transfer data between text files, word processor, spreadsheet, database, and project.

4. Track and account for cost information for your resources.

5. Change the working time for the project and make holidays non-working time.

6. Set up a recurring task and the projected schedule.

7. Identify the critical path and modify the critical path to get back on schedule.

8. Filter or highlight task and resource data and format the Gantt chart.

9. Create a project with documentation and analysis of the critical path.

The students are a mix of MET and Applied Technology who have a wide range of mathematical skills which can present some issues when teaching Excel. The MET students are required to take Calculus II while the Applied Tech students must complete Precalculus II, the prerequisite for the course. The topics in Table II are covered in detail and you will note that two of the objectives are on both lists.

Table II Course Objectives related to Spreadsheet Use

1. Use spreadsheet software to design structured, efficient, well-documented workbooks with data entry cells, summary results, statistics cells, and commented cells.

2. Create graphical presentations of data in standard technical formats and fit a curve to a data series.

3. Transfer data between text files, word processor, spreadsheet, database, and project.

4. Track and account for cost information for your resources.

The somewhat limited math background puts some limitations on what Excel functions can be introduced to only a small part of what the software can do. Here again the idea is to give them enough information for them to be able to pursue more advanced analysis if need be. The students seem to be more interested, or more at ease, with this part of the course than the PM part. This is due to the mathematical nature of the software that is easier to grasp for the students.

\section{Literature review}

In many project management courses taught in universities and colleges for technology and engineering students, Microsoft Excel is used ${ }^{1}$. The use of a spreadsheet approach alleviates (1) the need for institutions to purchase additional commercial project management software and (2) additional training of faculty and students on how to use the software. Spreadsheet programs, for example Microsoft Excel, are already entrenched in college computer laboratories with students and faculty having familiarity with their use. Using Excel therefore provides both an economical and convenient tool to use for project based projects in project management. Excel can be used 
for Gantt/milestone charts and Program Evaluation and Review Technique (PERT) diagrams. Although not as familiar to as many students and faculty as Excel, Microsoft Project is also used in project management courses. Additionally, Excel can also be used as a general tool for many different applications for technology and engineering.

Students in Engineering and Technology need to be successful in the competitive world therefore we need American engineers and technicians that are not only technically well-grounded but also talented in creativity, leadership, communication, and professionalism ${ }^{2}$. This includes project management and other soft skills necessary for success in the global world in which we now live. Technical competency, although necessary, is not sufficient for young engineers or other technically educated professionals who wish to quickly realize their potential in the consulting business, industry, or government. They must supplement technical competency with basic management proficiencies and leadership understanding if they are to be productive

In a survey around $2006^{3}$, which included more than 100 senior-level PM practitioners and $97 \%$ of the respondents said Project Management adds value to their organizations Consequently, to be successful in this work environment, it is crucial for engineers to have some level of Project Management knowledge. Companies would prefer that engineers gain this knowledge before they join the workforce. The big question asked is what are universities doing today to introduce tomorrow's employees to Project Management concepts?

The speed of technology progression has made evident that engineering graduates must have generic skills of a holistic nature in order to successfully meet future professional challenges ${ }^{4}$, In the paper by Ana Valeria Quevedo the impact of a project-based learning methodology was described on the improvement of generic skills. The methodology was used in an undergraduate industrial engineering project management course. Measurements of student knowledge and mastery of technical, contextual and behavioral skills were performed at the beginning and end of the course. Written questionnaires that measured the three dimensions were employed; the collected data was used in a statistical and a consistency analysis. The results indicated a significant improvement in student skills that can be attributed to the use of project based learning.

We would all like to have positive student evaluations that positively reflect our efforts in keeping both technical learning and skill acquisition on track in project courses ${ }^{5}$. To be effective in teaching project skills and keep the project on track we must properly identify the learning objectives to the student, improve achievement of those learning objectives and communicate assignment requirements.

In using projects to teach engineering design, the instructor faces the question of how to structure the process to insure an effective learning environment without compromising the independence and open-ended nature of the student's experience ${ }^{6}$. The learning from the project management should address these issues: 1) a milestone schedule, 2) regular project review meetings and memos and 3) design memos which document each design task as the project progresses. A memo portfolio provides a measure of individual student performance. Students turn in improved projects, learn some basic project management tools, and gain experience at regular documentation of their work. 
In many of the projects assigned to students in engineering and technology the following questions arise: Do the students put off their project assignments until the end of the term? Do they cram all their efforts into a very short period of time only to finish with an inferior project? Are there teamwork and cooperation issues? ${ }^{7}$ In this paper it addresses these issues and the important skills taught in the project management. These skills include how to write a project proposal, preparing a project plan, preparing a project schedule and preparing a project budget.

\section{Course Examples}

We have used several different approaches to cover the material in the course depending upon the instructor and the composition of the class. Some instructors have taught the course as a skills course using the Microsoft Press Step by Step books ${ }^{8,9}$ while others have focused on project management and problem solving using texts that are more oriented to Engineers ${ }^{10}$. A combination of the tools seems to work the best in our experience. The Step by Step books provide some very good hands-on exercises, but the students have a great deal of difficulty relating to some of the examples - particularly the film project in the Project book. However, even when we bring in engineering and technology examples there are some students who have difficulty - what is familiar to the METs is new to the Construction Management folks and viceversa.

One of the things that we have found useful is to alternate the teaching of the two different tools in a way the leads to development of a final project. The full use of both spreadsheets and project management software is complex enough that providing a short break between learning additional aspects of either program is beneficial, particularly when some related is being done in the other program. For example, we will use both Excel and Project to look at the costs of building a garage or similar small building. A typical series of assignments would be:

1. Use Excel do the calculations necessary to determine how much of each material is needed for the building based upon user entry of the building parameters such as the length, width, height, and roof pitch.

2. Use Project to create timeline and required resources to assemble the building. This includes both the different trades and some of the key equipment. It is sometimes difficult to keep this manageable when there are students who have taken construction estimating.

3. Use Excel to create the bill of materials for the building based upon the first assignment. This will include columns that read quantity, description, unit cost, and extended cost with the students responsible for collecting the unit cost data. A similar worksheet is then developed to estimate the labor costs.

4. Finally Project is used to account for the labor and equipment costs.

During this process the programs are compared and contrasted to show the strengths and weaknesses of each. In addition, the students are shown how to transfer data between the programs - particularly from the Excel labor costs into Project. The goal of this series of assignments is to show the students how to use multiple tools to create a project.

To teach graphical presentation and basic analysis of data we have found it very beneficial to use data that the students collect. The two most common assignments involve either the bounce heights of different balls or timing of balls dropped from the $1^{\text {st }}, 2^{\text {nd }}$, or $3^{\text {rd }}$ floor to the building 
basement. We start out by discussing the experiment that is to be conducted including repetition and using Excel to create a data collection sheet. We then break into groups and collect the data which gets everyone up out of their seats and away from the computers. Back in the classroom we enter the data and create a couple of different types of plots. One of the difficulties that arises is that they always want to create a line plot based upon their earlier instruction in Excel and it is one of the least useful plots for Engineering and Technology. We then apply trend lines to the scatter plots and use this to introduce the concept of least squares regression. Finally, we copy the plots into both Word and PowerPoint since they will need to do that in the final projects.

While the mechanics of Excel and Project are being taught using assignments like those listed above, the students are also being taught some of the basic concepts of project management. This starts with a discussion of the fact that projects are driven by customer needs and that it is critical to learn to listen to and really understand the customer's needs. The standard example is that the customer wants a nice sports car to commute to school - what they need is a good, reliable way to get to school, the bus pass provided as part of their fees does a very good job of meeting this need. It also includes the six phases of a project as listed in Table III and the tradeoffs that must be almost always be made during a project as shown in figure 1 .

Table III 6 Stages of a Project

1. Conception/Scoping

2. Study

3. Design

4. Development, Prototyping, and Testing

5. Production

6. Closing

Steps $3 \& 4$ are often an iterative process

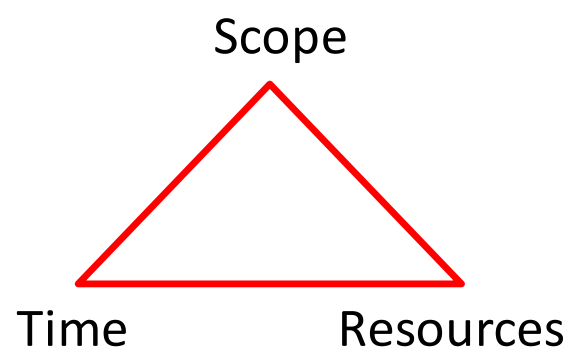

Figure 1 The Project Triangle

The students have to apply all of these tools during the last four weeks of the course when the form into teams of three to five to create and present a project of their choosing. These projects must be large enough and complex enough to utilize all of the tools and require effort by all of the team members, but not so complex to that they get lost in the details. The team that decided to recreate Disney World failed even though they were all very proficient in the use of the tools and some of them had project management experience. Currently we suggest that they plan on a project that will take approximately 90 - 120 days such as setting up a small business, building a house or similar building, or developing a piece of equipment - something that interests them. Once they have set up the timeline and resources they must step about half way through the project completing tasks and using resources to show they know how to account for the fact that things do not always go exactly as planned. At this point, the instructor presents them with a unique and unexpected disaster so they have to modify the critical path to get back on schedule. One of the most memorable was when the group setting up a bike shop was told that a couple of methheads broke in a trashed the place just before they received their inventory. Once they have developed a plan to get their project back they have to complete a final report presentation that is given to the class. They have to transfer data and charts from Excel and Project to Word and PowerPoint in order to tell the story of their project. The disaster and how their story about how they recovered from it is normally a highlight of the presentation. 


\section{Data analysis}

As part of our continuous improvement plan and analysis to meet the ABET 3a-k criteria we assess both how well the students met the course objectives as evaluated by the instructor and how well the students feel that the instructor covered the course objectives. Figure 1 shows the instructor evaluation of the student performance vs. the abbreviated terms for the course objectives as listed in Tables I and II. The scoring uses the standard $0-4$ scoring associated with a student GPA. There is a large range of performance with respect to both the course objective and the term in which the course was taught. The Spring 2012 scores show a particular large variation which was due in part to the instructor taking on a large overload midway through the term in order to cover when a colleague became ill.

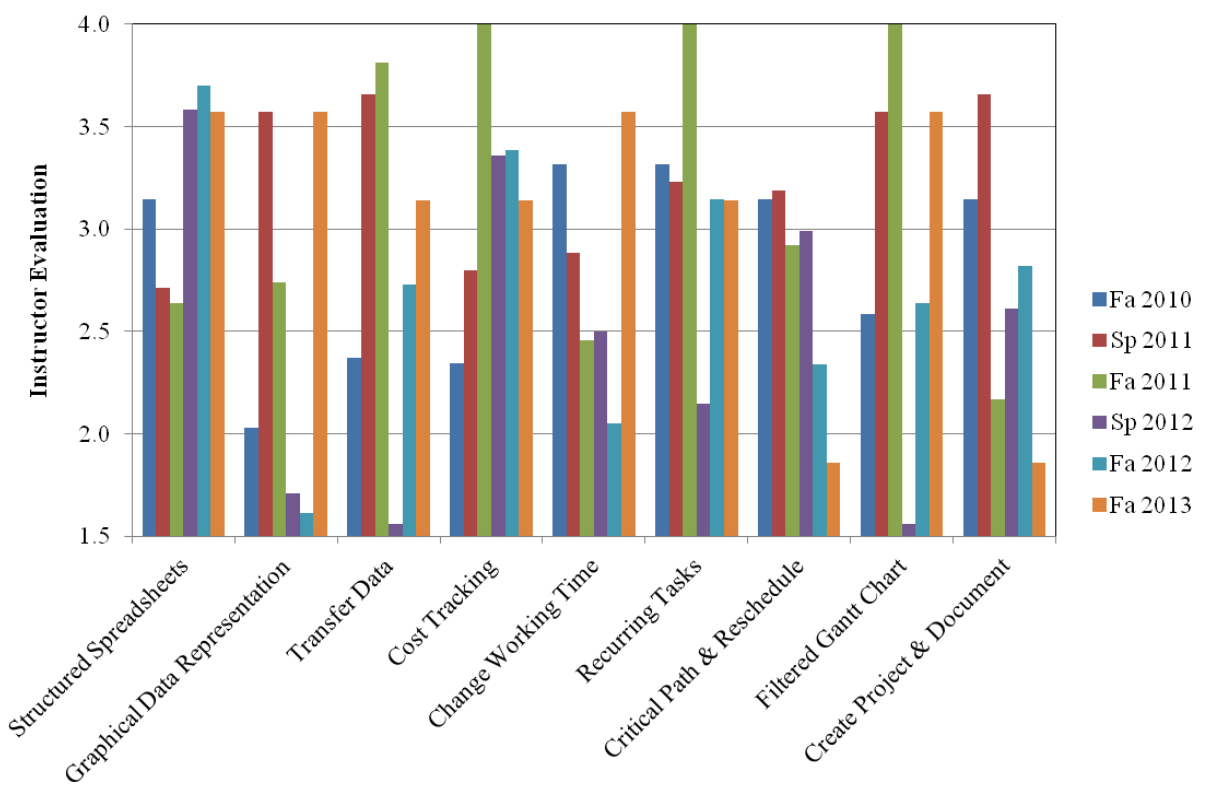

Figure 1 Instructor Evaluation of Student Performance

The student perceptions of how well the instructor covered the course objectives are shown in Figure 2. This data set includes three additional terms prior to the data set for the instructor evaluation of performance. The student population in these three terms was dominated by MET students while the later terms were more heterogeneous since the department had started to offer an ME degree that did not require this course. The student perception scores are more uniform than the instructor evaluation scores with notable exception of the Fall 2010 term. This was the first term the course was taught by a new instructor who brought in a very different approach to the course. He attempted to use MS Project and Excel to drive a single team project through the entire term - it was obvious that the students prefer a larger number of smaller assignments to learn the tools. The scores increased in the following terms as the instructor adapted his teaching style to the learning style of the students. 


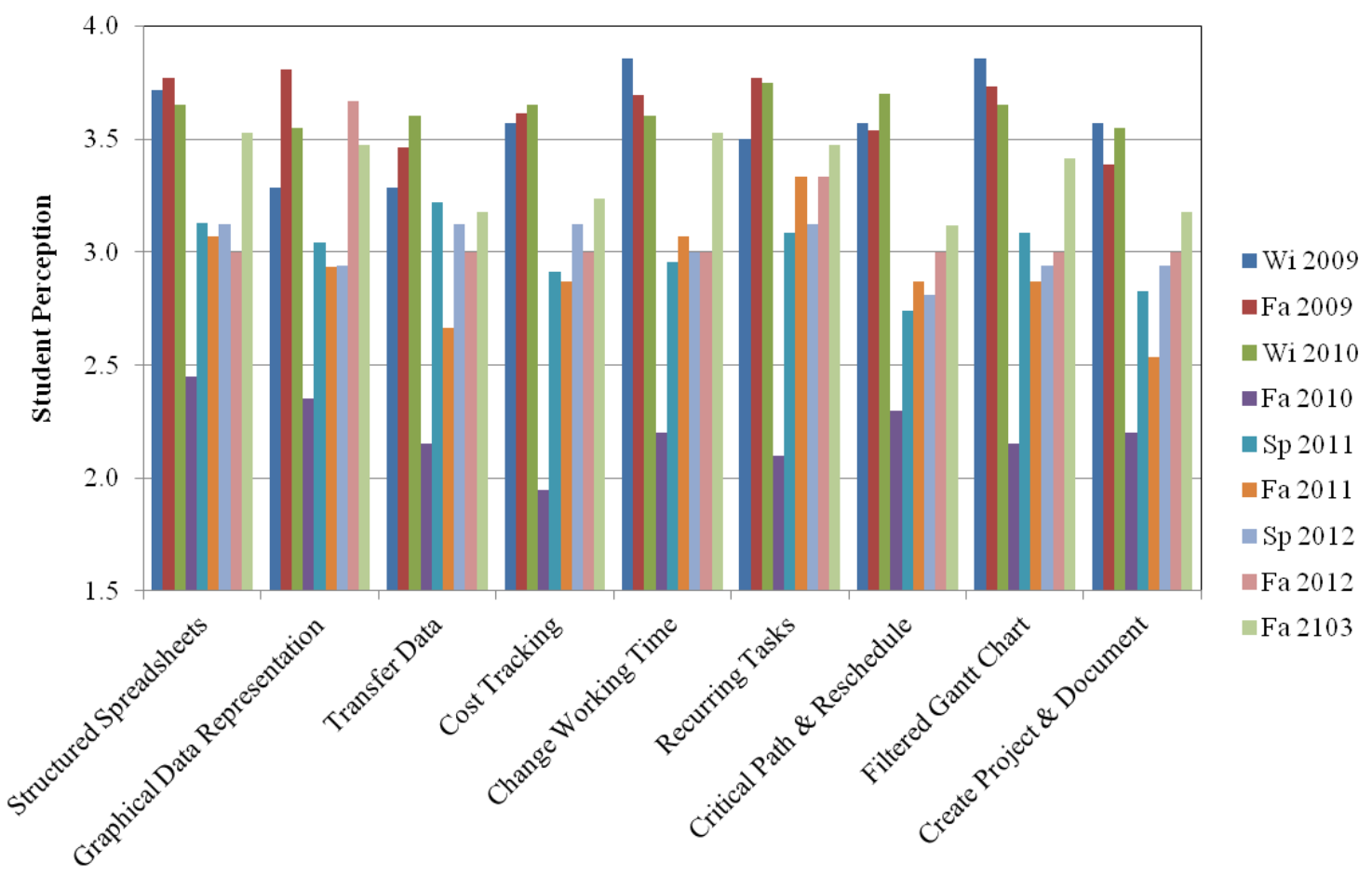

Figure 2 Student Perception of Instructor Coverage of the Course Objectives

It is interesting to note that the instructor evaluation of the student's work has generally lagged the student perception of how well the material was covered during the past few terms as shown in Figure 3. We attribute this to either the instructors developing better ways to present the information, increasing the instructor expectations, or a combination of the two.

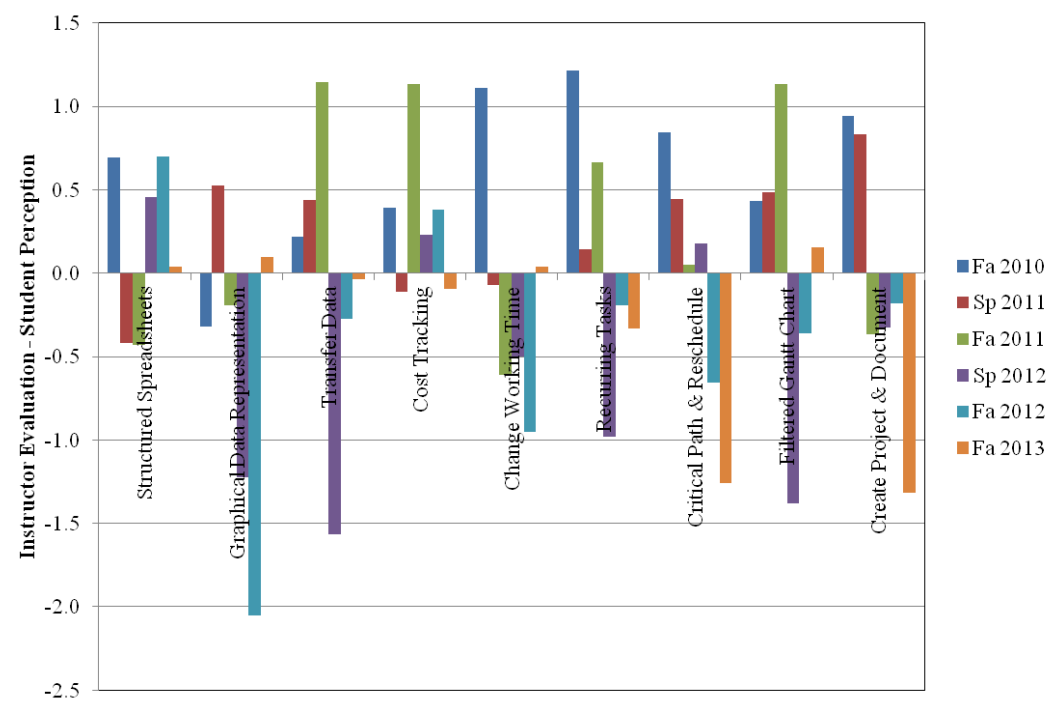

Figure 3 Difference between Instructor Evaluation and Student Perception 


\section{Conclusions}

Data handling and project management are taught using MS Excel and Project along with lectures/discussion of more general concepts. We have found that this is not an easy task, particularly when faced with a very diverse group of students including Mechanical Engineering Technology, Construction Management, and Applied Technology majors. Different approaches have been used ranging from following the MS Step by Step curriculum to quarter long team projects. We have found that a combination of short assignments that lead up to a final team project of the student's choice works best.

\section{Bibliography}

1. Madara M. Ogot and Gül E. Okudan, "Incorporating Project Management Methods into Engineering Design Projects: A Spreadsheet-based Approach", American Society of Engineering Education (2004)

2. James Plemmons, "The Prospect of Project Management Instruction in Undergraduate Engineering Education", American Society for Engineering Education, (2006)

3. James Conrad, "Determining How to Teach Management Concepts to Engineers", American Society for Engineering Education, (2006)

4. Ana Valeria Quevedo, "Improving Generic Skills among Engineering Students through Project-Based Learning in a Project Management Course", American Society for Engineering Education, (2013)

5. Donna C.S. Summers, "Practical Methods for Keeping Project Courses on Track", American Society for Engineering Education, (2001)

6. S. Scott Moor and Bruce D. Drake, "Addressing Common Problems in Engineering Design Projects: A Project Management Approach", Journal of Engineering Education July (2001)

7. Charlie P. Edmonson Donna C.S. Summers, "Using Project Management Skills to Improve the Outcome of Student Projects" American Society for Engineering Education Session 2457 (2004)

8. Frye, C.D., Microsoft Office Excel 2007: Step by Step, Microsoft Press, Redmond, WA (2007)

9. Chatfield. C., Johnson, T., Microsoft Office Project 2007: Step by Step, Microsoft Press, Redmond WA (2007)

10. Larsen, R.W., Engineering with Excel, 4th Ed., Pearson, Boston, MA 